\title{
Parents' Practices Associated with Aflatoxin Contamination and Control of Complementary Foods in Central Tanzania
}

\author{
Selestin Ngoma ${ }^{1,2}$, Bendantukuka Tiisekwa ${ }^{1,}$, Dismas Mwaseba ${ }^{3}$, Martin Kimanya $^{4}$ \\ ${ }^{1}$ Department of Food Technology, Nutrition and Consumer Sciences, Sokoine University of Agriculture, Morogoro, Tanzania \\ ${ }^{2}$ Department of Public Health, The University of Dodoma, Dodoma, Tanzania \\ ${ }^{3}$ Department of Agriculture Extension and Community Development, Sokoine University of Agriculture, Morogoro, Tanzania \\ ${ }^{4}$ Department of Food Biotechnology and Nutrition Sciences, The Nelson Mandela African Institution of Science and Technology, Arusha, \\ Tanzania
}

\section{Email address:}

selengoma@yahoo.com (S. Ngoma), tiisekwa@suanet.ac.tz (B. Tiisekwa), btiisekwa@yahoo.co.uk (B. Tiisekwa), dilmwase@yahoo.com (D. Mwaseba),martin.kimanya@nm-aist.ac.tz (M. Kimanya)

${ }^{*}$ Corresponding author

\section{To cite this article:}

Selestin Ngoma, Bendantukuka Tiisekwa, Dismas Mwaseba, Martin Kimanya. Parents' Practices Associated with Aflatoxin Contamination and Control of Complementary Foods in Central Tanzania. Journal of Food and Nutrition Sciences. Vol. 4, No. 6, 2016, pp. $152-161$. doi: $10.11648 /$ j.jfns.20160406.13

Received: October 22, 2016; Accepted: November 3, 2016; Published: November 25, 2016

\begin{abstract}
Parents' practices that are associated with aflatoxin contamination and control in complementary foods were studied in Central Tanzania. A descriptive cross-sectional survey using interviewer-administered structured pretested questionnaire was conducted among 364 randomly selected parents of children aged between 6-23 months, and the mean age (SD) of the respondents was 30 (8.3) years old. The majority 33.2\% of the participants harvest their crops in April followed by June which is $26.6 \%$, March which is $21.2 \%$ and May which is $19 \%$ of all the participants. Most processing activities like dehulling, milling, drying, storage were analysed. The statistical packages SPSS (version 21) computer software packages were used to analyze the data. The results of logistic regression model for dehulling crops confirmed that respondents with less than or with US\$ 22.8 as monthly income $(\mathrm{OR}=0.250,95 \%$ CI: $0.111-0.564)$ were significantly 0.3 less likely to dehull crops $(\mathrm{p}<0.05)$ than respondents who earned more than US\$. 22.8. On the other hand, petty trader participants $(\mathrm{OR}=3.712,95 \%$ CI: 1.420-9.699) were significantly almost 4 times more with a tendency of dehulling the crops $(p<0.05)$ than farmers. The study team recommends that parents should be trained on appropriate methods of drying, storage, and dehulling their crops after harvesting in order to control fungal and aflatoxin infestation. In addition, research on harvesting time, drying, storage, and dehulling practices of crops in Tanzanian is needed.
\end{abstract}

Keywords: Aflatoxin, Parents, Post-harvest Practices, Complementary Foods

\section{Introduction}

Aflatoxins are naturally occurring toxins produced by certain fungi, most importantly Aspergillus flavus and Aspergillus parasiticus, and they are widely recognized as a major health problem especially in hot, humid countries [1-5]. Major types of aflatoxins are B1, B2, G1, and $\mathrm{G} 2$; and metabolites of B1 and $\mathrm{B} 2$ are $\mathrm{M} 1$ and $\mathrm{M} 2$ respectively. AFB1 is the most potent of the aflatoxins. Aflatoxins have been rated as class 1A carcinogens by the International Agency for Research of Cancer [6-7]. They are heat stable and difficult to destroy during processing.
Aflatoxins B1 (AFB1) and B2 (AFB2) produced by A. flavus and aflatoxins $\mathrm{G} 1$ (AFG1) and $\mathrm{G} 2$ (AFG2) produced by $A$. flavus as well as A. parasiticus can contaminate not only maize and other cereals such as wheat and rice, but also groundnuts, pistachios, cottonseed, copra, and spices [8-9].

In many developing countries, poor diet and multiple communicable diseases are associated with malnutrition and growth faltering in infancy and childhood. In addition, dietary staples in some of these regions are frequently contaminated with fungal toxins such as the aflatoxins [10]. Aflatoxin production normally occurs in the field, particularly when 
stimulated by drought, stress, and high temperatures or during prolonged drying [11-14].

Aflatoxins contaminate many African dietary staples such as maize, groundnuts, rice and cassava, particularly under certain conditions like dry weather near crop maturity, high moisture during harvest, and inadequate drying and storage of crops [15]. Contamination can occur at any time from pre-harvest to storage of the crops [5, 15-17]. Food contaminated by aflatoxins is one of the most serious consequences that poor post-harvest management can have [16]. Poor post-harvest in warm humid areas and bad storage practices lead to rapid growth of the fungi and hence higher levels of toxins can occur [16,18]. This particularly happens in developing countries where appropriate measures for preventive actions are often overlooked [19-20]. Crops commonly affected by aflatoxins include maize, groundnuts, cottonseed, sorghum, millet, rice, Brazil nuts, pecans, walnuts, pistachio nuts, sesame and spices (particularly chilies), cassava, potatoes, legumes, pigeon peas, sunflower, simsim, peanuts, and products made from these crops [21-22].

Aflatoxin contamination in cereal grains is a worldwide concern especially in sub-tropical and tropical areas [21, 23]. In East Africa, aflatoxin exposure has also been directly correlated with reported daily intake of maize and fumonisin exposure which occurs almost entirely from maize [24]. Another major source of exposure to aflatoxin is through the consumption of groundnuts $[7,25]$.

Tanzania is among African the countries which lie in the latitudes between $40^{\circ} \mathrm{N}$ and $40^{\circ} \mathrm{S}$ which are susceptible to aflatoxin contamination [26-28]. Prevalence of aflatoxins contamination in crops in Tanzania is higher than that of the European Union aflatoxin standard (4 ppb) and that of USA (20 $\mathrm{ppb}$ ) and in many countries [27, 29-31]. Due to food shortage and low knowledge on fungal and aflatoxins contamination, these families sometimes eat undehulled, unsorted and mouldy crops without washing or winnowing them hence exposing themselves to high health risks of aflatoxin contamination in their diet. The specific objective of this study was to identify practices used that can contribute to levels of contamination of aflatoxins in complementary food in the households with children aged between 6-23 months in Central Tanzania. However, there is limited information on the parents' practices of post-harvest of crops which are used in the preparation of complementary food, aflatoxin contamination and control, and their associated health problems in Bahi, Mundemu, Handali, Mvumi Mission, Ikungi, Puma, Manyoni, and Maweni ward. These places are found in Dodoma and Singida regions in Central Tanzania. This study is part of a larger study with the overall objective of examining the influence of awareness, knowledge and actions of communities on childhood dietary exposure to aflatoxins in Dodoma and Singida regions.

\section{Materials and Methods}

\subsection{Research Setting}

The study was carried out in four districts of Bahi and Chamwino (in Dodoma region) and Manyoni and Ikungi (in Singida region) in Central Tanzania. Figure 1 and Figure 2 show a map of the study areas. According to the Tanzania National Bureau of Statistics [26], the population of Bahi District was 221,645, Chamwino was 330,543, Manyoni was 296,763, and Ikungi was 272,959. The major socio-economic activities found in the study areas are agriculture and livestock keeping. The major crops grown include maize, sorghum, millet, and groundnuts. Other crops are cowpeas, sunflower, cassava, Bambara nuts, paddy, simsim, and sweet potatoes [28, District Agricultural Officers]. The non-agricultural activities which include shop keeping, local brewing, civil services and petty trade are commonly practiced in towns and village centres [32]. A multistage sampling technique was used to select a total of 364 parents/caregivers with children aged between 6-23 months to participate in the study. The process involved simple random sampling at district, division, ward, village/street and sub-ward up to household level. Bahi District consists of 20 wards and out of these, two wards were selected randomly (Bahi and Mundemu) and from these wards, one village/street was selected from each (Bahi Sokoni and Mundemu respectively). Chamwino District consists of 32 wardsand out of these two wards were selected randomly (Handali and Mvumi Mission) and from those two wards, one village/street was selected from each (Handali and Ndebwe respectively). Manyoni District consists of 30 wards and out of these, two wards were selected randomly (Manyoni and Maweni) and from those two wards, one village/street was selected from each (Manyoni and Maweni respectively). Ikungi District consists of 26 wards and out of these, two wards were selected randomly (Ikungi and Puma) and from these wards, one village/street was selected from each (Ikungi and Puma respectively). The areas were selected because of their semi-arid condition which is characterized by high temperature during the day (up to $35^{\circ} \mathrm{C}$ ) and cool (to $10^{\circ} \mathrm{C}$ ) during the night. Both temperature and humidity favour the growth of fungi [32] signaling possibility of aflatoxins production [11].

\subsection{Research Design}

The research design was cross-sectional study. It involved the collection of data at one point (households) in line with the limited resources that were available for the study. Quantitative research method was employed in this study. A structured interview with both open and close-ended questions was developed and used to gather basic sociodemographic information from the participants with regard to post-harvest activities related to aflatoxin and its contamination in complementary foods and its health effects after consumption. Hence, this design was considered to be capable of providing some base-line information that could be used for future studies in the country. 


\subsection{Data Analysis}

Descriptive statistics (frequencies and percentages) were calculated to give characteristics of variables by using Statistical Package for Social Sciences (SPSS version 21.0) to analyze data after data cleaning. A $5 \%$ level of significance with $95 \%$ Confidence Interval (CI) was used throughout the study and an independent variable with p-value less than 0.05 was considered as statistically (significantly) associated with outcome variable. Logistic regression was done to identify which factors predicted parents/caregivers practices to minimize aflatoxins in complementary foods of their children.

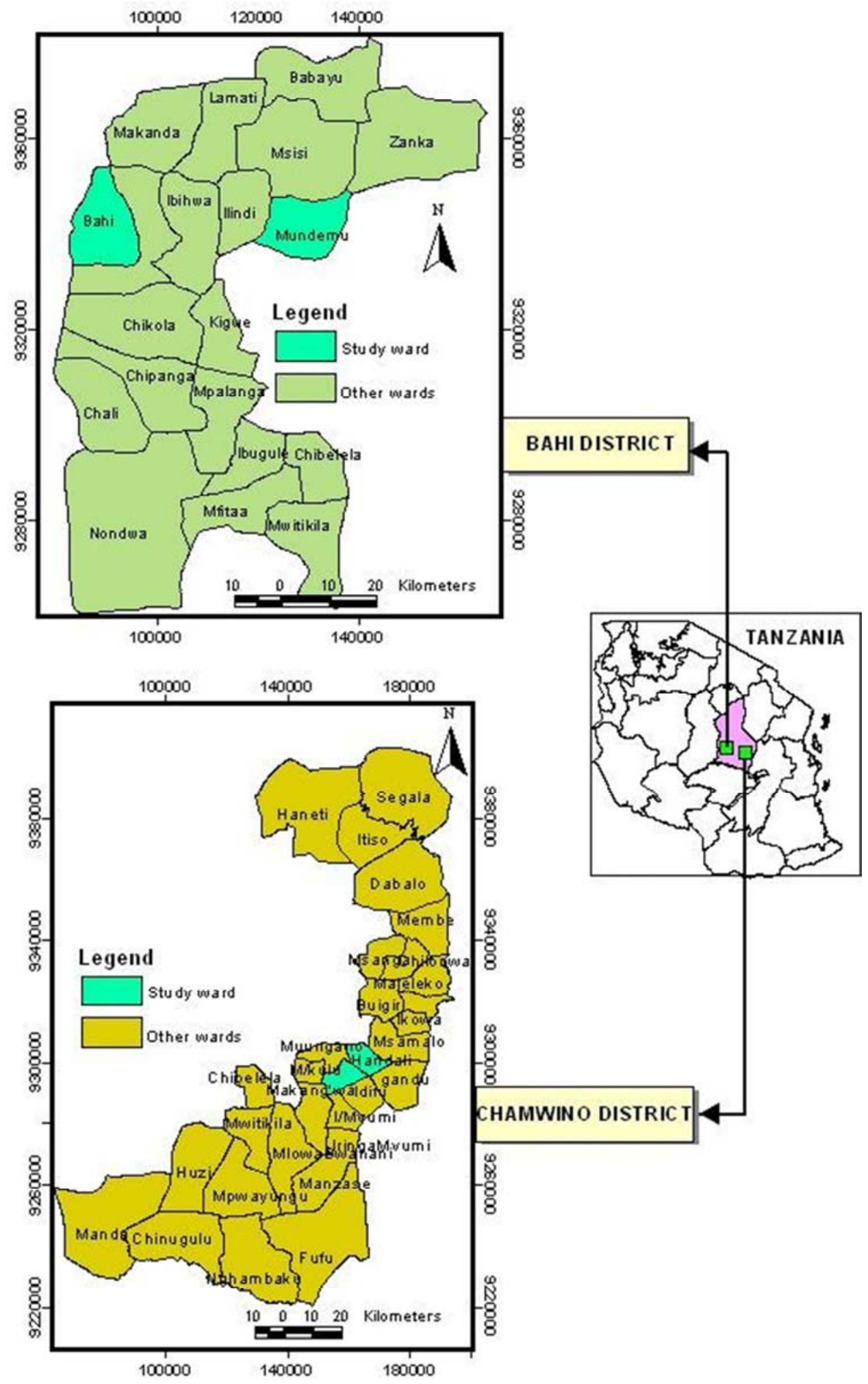

Figure 1. The Maps of Bahi and Chamwino Districts in Dodoma Region Showing Study Areas. 


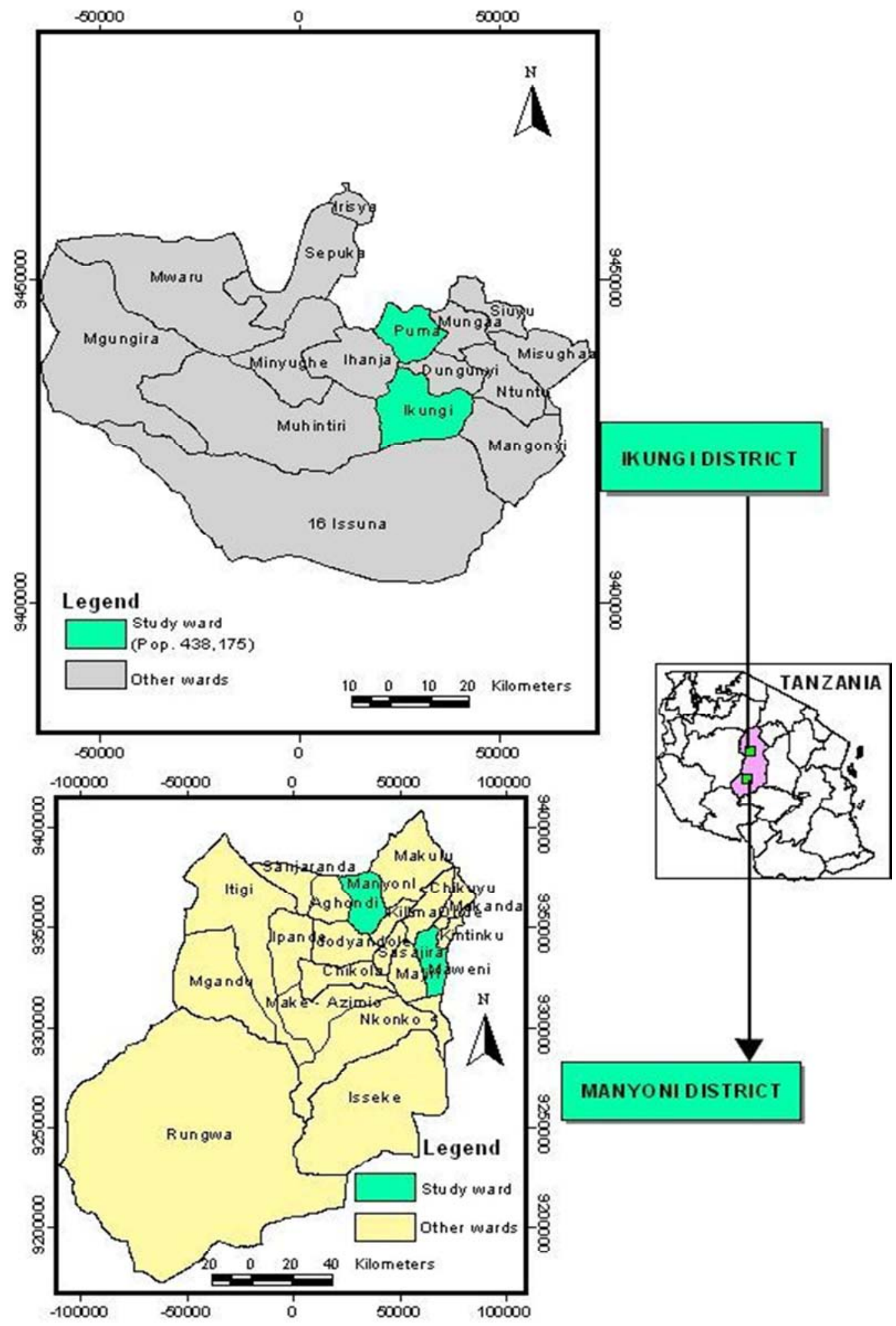

Figure 2. The Maps of Ikungi and Manyoni Districts in Singida Region Showing Study Areas.

\section{Results}

\subsection{Socio-Demographic Characteristics of Respondents}

Results in Table 1 show the distribution of parents/caregivers by socio-demographic characteristics in
Bahi, Chamwino, Ikungi, and Manyoni Districts. The age of parents/caregivers ranged from 17 to 80 years with mean age (SD) of 30 (8.3) years. About 270 (74.2\%) of the respondents were aged below or 34 years while respondents aged above 34 years were 94 (25.8\%). Mothers made up 331 (90.9\%) of the respondents. 
Table 1. Distribution of Parents/caregivers by Socio-demographic Characteristics.

\begin{tabular}{lll}
\hline Characteristics & Number (\%) & \\
\hline Age Group (Years) & & \\
$\leq 34$ & 270 & $(74.2)$ \\
$>34$ & 94 & $(25.8)$ \\
Monthly income (US\$) & & \\
$\leq 22.8$ & 256 & $(70.3)$ \\
$>22.8$ & 108 & $(29.7)$ \\
Level of education & & \\
Never been to school & 64 & $(17.6)$ \\
Partial primary & 49 & $(13.5)$ \\
Primary & 204 & $(56)$ \\
Partial secondary & 18 & $(4.9)$ \\
Secondary & 29 & $(7.9)$ \\
Respondent's occupation & & \\
Farmers & 287 & $(78.8)$ \\
House wives & 32 & $(8.8)$ \\
Employees & 10 & $(2.7)$ \\
Petty traders & 35 & $(9.6)$ \\
Marital status & & \\
In Union & 272 & $(74.7 \%)$ \\
Not in Union & 92 & $(25.3 \%)$ \\
\hline
\end{tabular}

\subsection{Harvesting Time Recorded During the Interview}

The majority, $33.2 \%$, of the participants harvests their crops in April followed by June which is $26.6 \%$ and March which is $21.2 \%$ of all the participants. Only $19 \%$ of the people in study areas harvest their crops in May every year depending on the type of crops planted.

\subsection{Dehulling Practices of Crops Used in the Preparation of Complementary Foods}

The majority, $81.3 \%$, of the respondents were not dehulling the crops used in the preparation of complementary foods.

Multiple Logistic Regression Model of Dehulling Practices of the Crops

Multiple logistic regression model was employed to find out how awareness and demographic characteristics were associated with dehulling of crops. The parameter estimates and associated odds ratios (OR) of the fitted model for dehulling the crops are presented in Table 2 . The results of the logistic regression model for dehulling the crops confirmed that respondents with less than or with US\$ 22.8 as monthly income $(\mathrm{OR}=0.250,95 \% \mathrm{CI}: 0.111-0.564)$ were significantly less likely to dehull crops $(p<0.05)$ than respondents who earned more than US\$22.8. On the other hand, occupation of the respondents was also a predictor of dehulling the crops. Petty trader participants $(\mathrm{OR}=3.712$, 95\% CI: 1.420-9.699) had significantly more tendency of dehulling the crops $(\mathrm{p}<0.05)$ than farmers. Though not significant $(\mathrm{p}=0.2673)$, employed $(\mathrm{OR}=3.349,95 \% \mathrm{CI}$ : $0.396-28.326)$ and housewives $(\mathrm{p}=0.7789, \mathrm{OR}=1.161,95 \%$ CI: 0.409-3.295) also had higher odds of dehulling the crops compared to farmer respondents. Other independent variables, namely age, education level, and marital status were not significantly associated with dehulling of crops.

Table 2. Parameter Estimates and Odds Ratios for Dehulling Crops.

\begin{tabular}{lllll}
\hline Variable & Parameter Estimate (se) & OR & 95\% CI & P-Value \\
\hline Awareness & Reference & & & Reference \\
No & $-0.2571(0.3973)$ & Reference & Reference & {$[0.355-1.685]$} \\
Yes & & 0.773 & & 0.5176 \\
Age (Years) & Reference & Reference & Reference & Reference \\
$\leq 34$ & $0.2625(0.3199)$ & 1.300 & {$[0.695-2.434]$} & 0.4120 \\
$>34$ & & & & \\
Monthly income (US\$) & Reference & Reference & Reference & Reference \\
$>22.8$ & $-1.3873(0.4154)$ & 0.250 & {$[0.111-0.564]$} & 0.0008 \\
$\leq 22.8$ & & & & \\
Education Level & Reference & Reference & Reference & Reference \\
Never been to School & $0.5092(0.5416)$ & 1.664 & {$[0.576-4.810]$} & 0.3471 \\
Partial Primary & $0.6309(0.4264)$ & 1.879 & {$[0.815-4.334]$} & 0.1390 \\
Primary & $0.2819(0.7828)$ & 1.326 & {$[0.286-6.148]$} & 0.7188 \\
Partial Secondary & $0.1586(0.7727)$ & 1.172 & {$[0.258-5.329]$} & 0.8373 \\
Secondary & & & \\
Occupation & Reference & Reference & Reference & Reference \\
Farmer & $0.1494(0.5322)$ & 1.161 & {$[0.409-3.295]$} & 0.7789 \\
House wife & $1.3115(0.4901)$ & 3.712 & {$[1.420-9.699]$} & 0.0074 \\
Petty trader & $1.2085(1.0894)$ & 3.349 & {$[0.396-28.326]$} & 0.2673 \\
Employee & & & & \\
MaritalStatus & Reference & Reference & Reference & Reference \\
Not in Union & $0.5465(0.3540)$ & 1.727 & {$[0.863,3.456]$} & 0.1226 \\
In Union & & & \\
\hline
\end{tabular}

$(\mathrm{se})=$ standard error

\subsection{Community Practices on Handling Crops}

In this study, the majority, $90.1 \%$, of all participants dried their crops before storage. Only, $9.9 \%$ of them did not dry their crops. The majority of the participants, $90.9 \%$, were milling their crops which were used in the preparation of complementary foods. During the survey, about half, $49.2 \%$, of the respondents were seen drying their crops on 
roofs (their roofs were normally covered with mud), while $32.7 \%$ of the participants placed their crops directly on the soil for drying and $8.2 \%$ of them dried in traditional granaries. Only $9.9 \%$ of the respondents did not dry their crops at all. (See Figure 3).
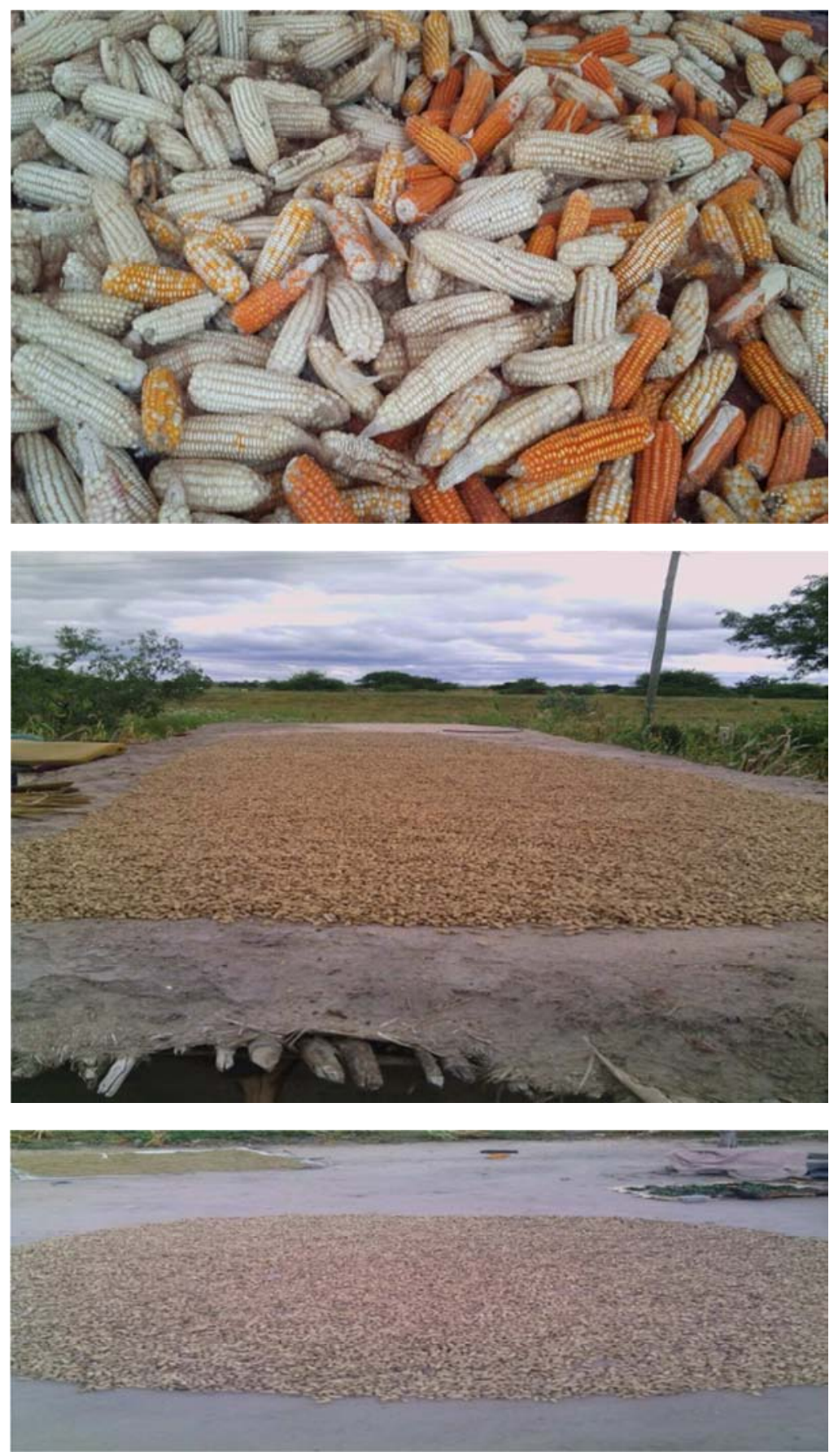

Figure 3. From left and down: Drying Crops Directly on the Soil and on the Roof.

The findings show that $90.9 \%$ of the respondents normally stored their crops after harvesting while the rest did not. In addition, results revealed that almost half, $50.5 \%$, of the respondents storedtheir crops in bags, $40.4 \%$ stored in the traditional granaries and only $9.1 \%$ of them did not storetheir crops at all. Also, in the study areas, the majority, $72.5 \%$, of the participants used their homegrown crops for food consumption while $27.5 \%$ of them used them for both consumption and selling. Further results from this study revealed that more than half, $54.4 \%$, of the respondents declared that their crops usually got mouldy during storage. Moreover, the majority, $36.5 \%$, of the parents provided both special and family foods to their babies while others provided only family food. The study also revealed that the majority, $53.0 \%$ of the parents, after harvesting, gave the mouldy feed to animals while $38.5 \%$ of participants used it in local brewing and $8.5 \%$ consumed the mouldy food. In 
addition, the majority, $54.4 \%$, of the participants said that they left their residual crops after harvest in the field while $36.5 \%$ gave them as feed to animals.

\section{Discussion}

This study investigated the parents' practices that contribute to aflatoxin contamination and control in complementary foods in Central Tanzania. A total of 364 parents with children aged between 6-23 months participated in the study. Harvesting time was very important in aflatoxins contamination and control. Timing of the harvest was a key factor in aflatoxins reduction. Harvesting crops in March or April was called early harvesting in the study areas. Early harvesting and the rapid drying of crops in moisture content levels below $15 \%$ are believed to effectively stop aflatoxin accumulation [33]. However, in these study areas, nothing was used to measure the moisture content due to lack of money to buy the instrument. In that situation, food quality was likely to be compromised. In these study areas, late harvesting was between May and June during which the crops could easily get contaminated by fungus since the crops had over matured, cracks, birds were prone to damage and insects could infest them either on the ground soil or as standing plants. The influences of delayed harvest on contamination are most severe when crops are caught by rain just prior to or during harvest [34]. Therefore, late harvesting (after the second half of May to June) in the study areas not only causes an increase in cracking of some crops but also provides further exposure to aflatoxin production and contamination. Damage by birds, pests, shell discoloration and falling down of crops/seeds on contaminated soil surface are other risk factors associated with late harvesting [35-39]. Delayed harvesting occurred in areas where farmers left the crop to dry completely on the field as it happened in some places in the study areas.

Dehulling is the process of removing the pericarp from the grain. In these study areas, dehulling was done by using stones or mortar and pestles, the same as what was reported by Fandohan [40] in Benin, West Africa. Generally, in these study areas dehulling was done by women and this is also the same as revealed in Benin [40]. It has been reported that dehulling removes most of the toxins in the bran and germ fractions [41]. From the survey done by Abt Associates [27, 42] in three districts (Kongwa, Bukombe, and Njombe) in Tanzania, it was revealed that farmers did not know about aflatoxins. Their level of knowledge was very low and agricultural extension officers were not trained in mycotoxin and aflatoxin, the same as it was the case in the current study. Furthermore, parents with high monthly income were more likely to dehull the crop than those with low monthly income. In addition, parents who were petty traders were more likely to dehull their crops than farmers. Therefore, it is very important to train parents about mouldy infestation in the crops and aflatoxin and its control because they use it as blended flour that is mixed with maize, groundnuts and others crops in the preparation of complementary foods. In the study done in Kenya, the results revealed that reduction in aflatoxin levels was realized during dehulling of maize grains as evidenced by the lower levels of aflatoxins in dehulled maize; the percentage of reduction in aflatoxin levels was between $5.5 \%$ and $70.0 \%$ with a mean of $46.6 \%$ [43]. Also, in the study done in Zimbabwe, it was revealed that undehulled crops had higher percentage of aflatoxin levels when compared to the dehulled crops [44]. Also these results emphasize that there is a need of dehulling the crops before eating. In Benin-West Africa, women used some unit operations like sorting, winnowing, washing, crushing, and dehulling to remove significant amounts of aflatoxins and fumonisins in maize and maize products [45]. Also, [46] noted the effects of processing aflatoxin reduction. Furthermore, drying, storage, and dehulling reduce aflatoxin levels and can be recommended as a decontamination method developed mainly in the African countries where it is still uncommon but these technologies should be improved to reduce women workload. Therefore, it is revealed in the current study that people might have been consuming contaminated foods through their diets because the majority does not de-hull their crops before milling or cooking in the preparation of foods for the babies or food for the family.

This study revealed that parents dried their crops on the roof (mud roofed) and others put them directly on the soil while few used traditional granaries or containers made by thatches or bamboo. These results are not similar to the study done [47] which revealed that about half of the families surveyed in Kenya reported that they take maize home to dry in tarpaulins, which would limit direct exposure of the maize to dirt. However, this study reflects the one done in Mali because nearly half of those families surveyed reported that they dried groundnuts in large piles on the ground. Such direct contact with the soil is problematic because aflatoxins are a toxic substance emitted by fungi that are plentiful in agricultural soil in the tropics and sub-tropics regions [21, 48].

As it was revealed in the current study, the greater part of parents normally stored their crops after harvesting while others did not. Again, as it has been explained that poor postharvest practices and storage conditions are known to increase aflatoxin prevalence. This study revealed that almost half, $50.5 \%$, of respondents stored their crops in the polythene (nylon) bags, $40.4 \%$ stored their harvested crops in the traditional granaries and only $9.1 \%$ of them did not store their crops. These results contrast with the study done in Kenya which observed that about 30 percent of the respondents reported that they left maize uncovered in the fields and the most common reported storage practices were either using a room in the house or an improved granary with a wooden wall [49]. As it is in Tanzania, Kenya and a few Malian farmers, use of the storage structures as traditional granaries is most common. As a result of poor food storage, aflatoxin levels are increased in storage and in the markets, suggesting that current crops drying and storage practices are inadequate. These may be due to not only lack of knowledge on the importance of storing crops for future use, but also some of them did not have money to buy bags for storage and did not have enough food for storage. For example, there 
were no pallets or wood used during storage but farmers put their crops directly on the floor making it easy for the crops to be infested by insects such as termites and rodents. It was further revealed that sometimes these farmers used nylon bags (sacks) during storage of crops because they were cheap and easily available compared to sisal sacks. Also this study revealed that almost more than half of the respondents declared that their crops got mouldy during storage but they did not know whether it was aflatoxin or not because the word "aflatoxin" was a new terminology to them. This is inconsistent with the findings [21] who reported that it is suitable to keep the grains from contact with the soil, keep them in wooden pallets or on concrete floor and ensure adequate ventilation in the storage facility which helps to prevent an increase in moisture content, insect, and rodent infestation during storage; for that is a critical measure against aflatoxin contamination. Also, [50] in Kenya reported that the majority of the farmers did not protect their grains against scorching sunshine, termites and pests damage, and more importantly, mould colonization. [51], in his study on aflatoxins level on locally grown maize from Makueni District in Kenya noted that nylon sacks (bags) were commonly used as grain storage containers by $89 \%$ of the respondents. These sacks maintain moisture and prevent free air circulation within the grain store hence they promoting aflatoxin contamination while the sisal sacks which are known to keep minimal moisture content reduce aflatoxin contaminations and were used by only $10 \%$ of the people.

This study shows that more than half of the parents provided animals (cow, hens and ducks) with the mouldy feeds after harvesting while some of them were using them as local brewing ingredients and others consumed the mouldy food by mixing it with good one and milling it without even sorting or winnowing. Parents used mouldy food both for special and family food for their children, thus exposing themselves to great health risks of eating contaminated foods with aflatoxins. The parents in these study areas should be trained on appropriate methods of drying, storage and dehulling their crops after harvesting in order to control fungal and aflatoxin infestation. Also, harvesting time is vital in order to manage aflatoxin contamination.

\section{Conclusion}

Most of the parents in these study areas engage in smallscale, mixed farming that includes some livestock. Maize, sorghum, and groundnuts are the primary dietary staple and the main crops produced in these study areas. These crops are very susceptible to mouldy if inappropriately processed. At harvest, farmers store most of their crops for household consumption in poor storage facilities and sell the rest (if they harvest enough) to meet other household needs. When household crops stored are finished, farmers sell their livestock and purchase crops from the market. Due to food shortage and low knowledge on fungal and aflatoxins contamination, these families sometimes eat undehulled, unsorted and mouldy crops without washing or winnowing them hence exposing themselves to high health risks of aflatoxin contamination in their diet.

This study strongly recommends that parents in Central Tanzania need to be made aware of potential health dangers of fungal and aflatoxin production in their crops through enhanced involvement of agricultural extension services in farming communities. The agricultural extension officers and village health officers need to be trained on aflatoxin awareness and knowledge since they are also unaware of these aflatoxins. The agricultural extension officers need to know issues that can result in fungal infection and aflatoxin production and how contamination of crops can be reduced before they are used in the preparation of complementary foods. The agricultural extension officers should in turn advise farmers on good agricultural practices that can reduce aflatoxins contamination of crops such as good pre and post harvesting practices.

\section{References}

[1] Bennett, J. W. and M. Klich. 2003. Mycotoxins. Clinical Microbiology Review. 16:497-516.

[2] CAST (Council for Agriculture Science and Technology), (2003). Mycotoxins: Risks in plant, animal and human systems. Taskforce Report No. 139. Ames, IA: Council for Agriculture, Science and Technology.

[3] Williams, J. H., Phillips, T. D., Jolly, P. E., Stiles, J. K., Jolly, C. M. and Aggarwal, D. (2004). Human aflatoxicosis in developing countries: a review oftoxicology, exposure, potential health consequences, and interventions. American Journal of Clinical Nutrition. 80:1106-1122.

[4] Manetta, Anna Chiara, (2011). Aflatoxins: Their Measure and Analysis, Aflatoxins Detection, Measurement and Control, Dr Irineo Torres-Pacheco (Ed.), ISBN: 978-953-307-711-6.

[5] Ephrem, Guchi, (2015). Implication of Aflatoxin Contamination in Agricultural Products American Journal of Food and Nutrition. Vol. 3, No. 1, 12-20.

[6] IARC (International Agency for Research on Cancer), (2002). Some traditional herbal medicines, some mycotoxins, naphthalene and styrene. IARC monographs on the evaluation of carcinogenic risks to humans (vol. 82). Lyon, France: World Health Organization, pp. 1-556.

[7] IARC (International Agency for Research on Cancer), (2012). Agents Classified by the IARC Monographs. Vol.1, No.104.

[8] Rustom, I. Y. S. (1997). Aflatoxin in food and feed: Occurrence, legislation and inactivation by physical methods. Food Chemistry, 59, pp. 57-67.

[9] Piermarini, S., Volpe, G., Michelle, L., Moscone, D., and Palleschi, G. (2009). An ELIME array for detection of aflatoxin B1 in corn samples. Food Control, 20, 371-375.

[10] Wild, C. P. and Gong, Y. Y. (2010). Mycotoxins and human disease: A largely ignored global health issue. International Agency for Research on Cancer, 69372 Lyon Cedex 08, France and Molecular Epidemiology Unit, LIGHT Laboratories, University of Leeds, Leeds, LS2 9JT, UK. Carcinogenesis vol. 31 No. 1 pp. 71-82, 2010. 
[11] Cotty, Peter J. and Jaime-Garcia, Ramon (2007). Influences of climate on aflatoxin producing fungi and aflatoxin contamination. International Journal of Food Microbiology 119:109-115.

[12] Wu. F., Bhatnagar. D., Bui-Klimke1. T., Carbone. I., Hellmich. R, Munkvold. G, Paul. P, Payne. G. and Takle. E. (2011). Climate change impacts on mycotoxin risks in US maize. World Mycotoxin Journal 4 (1): 79-93.

[13] Hamidou, F., Rathore, A, Waliyar, F. and V. Vadez, V. (2014). Although drought intensity increases aflatoxin contamination, drought tolerance does not lead to less aflatoxin contamination. Field Crops Research 156:103-110.

[14] Farfan, Ivan D. Barrero, Gerald N. De La Fuente, Seth C. Murray, Thomas Isakeit, Pei- Cheng Huang, Marilyn Warburton, Paul Williams, Gary L. Windham, Mike Kolomiets (2015). Genome Wide Association Study for Drought, Aflatoxin Resistance, and Important Agronomic Traits of Maize Hybrids in the Sub-Tropics. PLOS ONE. DOI:10.1371/journal.pone.0117737.

[15] Hell, K., Ognakossan, K. E., Tonou, A. K., Lamboni, Y., Adabe, K. E. and Coulibaly, O., (2010). Maize stored pests control by PICS-Bags: Technological and economic evaluation.

[16] Hell, K. and Mutegi, C. (2011). Aflatoxin control and prevention strategies in key crops of Sub-Saharan Africa. African Journal of Microbiology ResearchVol. 5(5) pp. 459466.

[17] Wagacha, J. M., and J. W. Muthomi. (2008). "Mycotoxin Problem in Africa: Current Status, Implications to Food Safety and Health and Possible Management Strategies." International Journal of Food Microbiology 124: 1-12.

[18] Craufurd, P. Q., Prasad, P. V. V., Waliyar, F. and Taheri, A. (2006). Drought, pod yield, pre-harvest Aspergillus contamination on peanut in Niger. Field Crops Research 98:20-29.

[19] International Crops Research Institute for the Semi-Arid Tropics (ICRISAT), (2000). BP 320, Bamako, Mali; DOI 10.3920/WMJ2014.1766 245.

[20] International Crops Research Institute for the Semi-Arid Tropics (ICRISAT) and National Smallholder Farmers' Association of Malawi (NASFAM). (2009). Assessing Occurrence and Distribution of Aflatoxins in Malawi-Project Final Report.

[21] Strosnider, H., Azziz-Baumgertner, E., Banziger, M., Bhat, R. V., Breiman, R. and Brune, M. (2006). Workgroup report public health strategies for reducing aflatoxin exposure in developing countries. Environmental Health Perspective 114:1B9B-1903.

[22] Mkoka, C., 2007b. Farmers use cheap technology to fight fungus. SciDevNet 27 July, 2007.

[23] Guan. S, Zhou. T, Ym. Y, Xie. M, Ruan. Z and Young. J. G. (2011). Microbial strategies to control aflatoxins in food and feed. World Mycotoxin Journal, 4 (4): 413-424.

[24] Kimanya, M. E., De Meulenaer, B., Tiisekwa, B., NdomondoSigonda, M., Devlieghere, F. and Van Camp, J. (2008). Cooccurrence of fumonisins with aflatoxins in home-stored maize for human consumption in rural villages of Tanzania. Food Additive Contamination Part A Chemical Analytical Control Exposure Risk Assessment 25:1353-1364.
[25] Liu, Y. and Wu, F., (2010). Global burden of aflatoxin-induced hepatocellular carcinoma: a risk assessment. Environmental Health Perspectives 118: 818-824.

[26] National Bureau of Statistics, Tanzania (NBS), (2012). "Statistical Abstract,". Nbs.g.tz.

[27] Abt Associates Inc (2012). Country and Economic Assessment for Aflatoxin Contamination and Control in Tanzania Preliminary Findings. Contract \#9678.2.

[28] United Republic of Tanzania (URT, 2013). "Population Distribution by Administrative Units," Nbs.go.tz. p. 2-6.

[29] Shirima, Candida P., Kimanya, Martin E., Kinabo, Joyce L., Routledge, Michael N., Srey, Chou., Wild,Christopher P. and Gong, Yun Yun. (2013). Dietary exposure to aflatoxin and fumonisin among Tanzanian children as determined using biomarkers of exposure. Journal of Molecular Nutrition of Food Research. 57(10): 1874-1881.

[30] Kimanya, Martin E., Shirima, Candida P., Magoha, Happy, Shewiyo, Danstan H., De Meulenaer, Bruno, Kolsteren, Patrick and Gong, Yun Yun. (2014). Co-exposures of aflatoxins with deoxynivalenol and fumonisins from maize based complementary foods in Rombo, Northern Tanzania. Journal of Food Control 41: 76-81.

[31] Kamala, Analice, Kimanya, Martin, Haesaert, Geert, Tiisekwa, Bendantuguka, Madege, Richard, Degraeve Szanne, Cyprian Cyprian and Meulenaer, Bruno (2016). Local post-harvest practices associated with aflatoxin and fumonisin contamination of maize in three agro ecological zones of Tanzania. Food Additives and Contaminants: Part A. Volume 33: 551-559.

[32] Morris, Mike John Butterworth, Richard Lamboll, Evelyn Lazaro, Faustin Maganga, and Neil Marsland. (2001). Understanding Household Coping Strategies in Semi-Arid Tanzania Household Livelihood Strategies in Semi-Arid Tanzania: Synthesis of Findings, Annex.

[33] Gourama, H. and Bullerman, L. B. (1995). Aspergillus flavus and Aspergillus parasiticus. Aflatoxigenic fungi of concern foods and feeds: A Review. Journal of Food Protect, 58: 1395-1404.

[34] Jaime-Garcia, R. and Cotty, P. J. (2003). Aflatoxin contamination in commercial cottonseed in South Texas. Phytopathology 93, 1190-1200.

[35] Sommer, N. F., Buchanan, J. R. and Fortlage, R. J. (1986). Relation of early splitting and tattering of pistachio nuts to aflatoxin in the orchard. Phytopathology, 76(7): 692-694.

[36] Doster, W. A. and Michailides, T. J. (1999) Relationship between shell discoloration of pistachio nuts and incidence of fungal decay and insect infestation. Plant Diseases, 83: 259-264.

[37] Moradi, M. (2005) Ecology of Aspergillus flavus and Aspergillus niger groups in pistachio orchards in Kerman province, Iran. IV International Symposium on Pistachios and Almonds.

[38] Moradi M and Javanshah A. (2005) Distribution of aflatoxin in processed pistachio nut terminals.

[39] Moradi, M. and Mirabofathy, M. (2007) Population density of Aspergillus flavus and Aspergillus niger at different kinds of pistachio processing terminals.

[40] Fandohan, P. (2004). Fusarium infection and mycotoxin contamination in pre-harvest and stored maize in Benin, West Africa. PhD Thesis, University of Pretoria, South Africa. 196p. 
[41] Fandohan, P., Ahouansou, R., Houssou, P., Hell, K. (2006). Impact of mechanical shelling and dehulling on Fusarium infection and fumonisins contamination in maize. Food Additive Contamination. 2006, 23, 415-421.

[42] Abt Associate (2013). Country and Economic Assessment for Aflatoxin Contamination and Control in Tanzania. Preliminary Findings. Prepared for the Meridian Institute in support of Partnership for Aflatoxin Control in Africa.

[43] Mutungi C, Lamuka P, Arimi S, Gathumbi J, Onyango C. (2008). The fate of aflatoxins during processing of maize into muthokoi-A traditional Kenyan food. Food Control. 2008; 19:714-721.

[44] Siwela, Andrew H, Siwela, Mthulisi, Matindi, Gibson, Dube, Shad reck and Nozipho Nziramasanga (2005). Decontamination of aflatoxin-contaminated maize by dehulling. Journal of Science of Food and Agriculture 85:2535-2538.

[45] Fandohan. P, Zoumenou. D, Hounhouigan. D. J, Marasas, W.F.O., Wingfield, M.J. and Hell, K. (2005). Fate of aflatoxins and fumonisins during the processing of maize into food products in Benin. International Journal of Food Microbiology 98 (2005) 249-259.

[46] Park, D. L. (2002). Effect of processing on aflatoxin.
Advances in Experimental Medicine and Biology 504, 173179.

[47] Narrod, Clare (2013). Aflatoxins: Finding solutions for improved food safety reducing Aflatoxins in Africa's crops: Experiences from the Aflacontrol Project. 2020, Vision.

[48] Abbas H. K, Wilkinson J. R, Zablotowics R. M, Accinelli C, Abel C. A, Bruns HA, Weaver Ma. (2009). Ecology of Aspergillus flavus, regulation of aflatoxin production, and management strategies to reduce aflatoxin contamination of corn. Toxin Reviews, 28:142-153.

[49] Bett, C., H. de Groote, and C. Narrod. 2012. Economic Importance of Maize Storage Structures in Kenya. Aflacontrol Working Paper. Unpublished, International Food Policy Research Institute, Washington, DC.

[50] Lanyasunya, T. P., Wamae, L. W., Musa, H. H., Olowofeso, O., Lokwaleput, I. K. (2005). The risk of mycotoxins contamination of dairy feed and milk on smallholder dairy farms in Kenya. Pakistan Journal of Nutrition 4:162-169.

[51] Mwihia, J. T, Straetmans, M, Ibrahim, A, Njau, J, Muhenje, O, Guracha, A. (2008). Aflatoxin levels in locally grown maize from Makueni District, Kenya. East African Medical Journal, 85:311-317. 